\title{
Apresentação: Cem anos da observação do eclipse solar de Sobral
}

\author{
Silvio R.A. Salinas ${ }^{*+1}$ \\ ${ }^{1}$ Instituto de Física, Universidade de São Paulo, São Paulo, SP, Brasil
}

Recebido em 2 de Outubro de 2019. Aceito em 03 de Outubro de 2019

Nesse ano de 2019 estamos comemorando o centenário da observação de um eclipse total do Sol, em Sobral, no Ceará, que se tornou a experiência astronômica mais famosa do século XX. A análise das placas fotográficas obtidas em Sobral proporcionou uma fortíssima evidência da curvatura dos raios da luz provenientes das estrelas nas vizinhanças do Sol. Os valores numéricos obtidos para os ângulos de deflexão foram compatíveis com as novas propostas da teoria da gravitação de Einstein, e estavam em desacordo com as previsões da mecânica clássica newtoniana. $\mathrm{O}$ anúncio dos resultados obtidos pela expedição inglesa enviada a Sobral, com apoio de uma equipe brasileira liderada por Henrique Morize, diretor do Observatório Nacional, foi comunicado pelo astrofísico Arthur Eddington numa sessão solene da Royal Society de Londres, no dia 6 de novembro de 1919. O universo clássico do inglês Sir Isaac Newton, fundador da Royal Society, deveria ser substituído pelo "espaço-tempo curvo" de um físico alemão. Albert Einstein já era bem conhecido entre os seus pares, principalmente devido aos seus trabalhos do "annus mirabilis" de 1905, que incluíram a teoria da "relatividade restrita", primeira unificação de espaço e tempo, e a utilização das ideias recentes de Planck para a explicação do efeito fotoelétrico (ver a edição especial sobre o "ano internacional da física" da nossa Rev. Bras. Ens. Fis., volume 27, número 1, março de 2005). Depois do anúncio de Eddington em novembro de 1919, realizado na própria casa de Newton, a notícia transbordou para a imprensa internacional, e Einstein virou uma estrela científica mundial, certamente o cientista mais conhecido do século XX (Einstein foi recebido com uma carreata nas ruas de Nova York em abril de 1921, no mesmo ano em que ganhou o prêmio Nobel; um pouco depois, realizou uma viagem à América do Sul, visitando o Brasil em maio de 1925).

Embora tenham aparecido no país diversas matérias sobre o centenário da observação do eclipse de Sobral, incluindo publicações no boletim da SBPC e na revista da Fapesp, embora tenha sido realizada uma sessão comemorativa da SBPC na própria cidade de Sobral e uma

\footnotetext{
*Endereço de correspondência: ssalinas@if.usp.br

†Editor da Revista Brasileira de Ensino de Física.
}

exposição de instrumentos no Observatório Nacional, nós decidimos manter essa pequena "edição especial" da Revista Brasileira de Ensino de Física, com o objetivo de mesclar aspectos históricos, às vezes pouco conhecidos, com elementos de conteúdo físico, tão essenciais para a formação dos nossos alunos.

Essa edição especial se deve ao incentivo do nosso colega Ildeu Moreira, que atualmente exerce a presidência da SBPC, sendo obrigado a se dedicar em tempo integral ao exorcismo dos fantasmas anticientíficos que ainda infestam o mundo contemporâneo. Mas o trabalho maior de angariar e reunir as contribuições recaiu sobre o nosso editor associado Nelson Studart, que também participou da redação de pelo menos dois artigos dessa edição.

Os primeiros cálculos de Einstein para a deflexão da luz foram publicados em 1911, mas foi em trabalho de 1916 que Einstein conseguiu chegar a um resultado a partir da sua formulação da relatividade geral. O cálculo inicial usava a teoria ondulatória da luz, mas o raio de luz era sujeito à força de atração usual da gravidade. Esse resultado se tornou conhecido como newtoniano. O físico, matemático e astrônomo britânico, Arthur Eddington, imaginou três possibilidades para a deflexão da luz de uma estrela devido à presença de um corpo massivo como o Sol: (i) nenhuma deflexão, de acordo com as concepções ondulatórias mais aceitas na física da época; (ii) deflexão por um ângulo pequeno, cerca de 0,80 segundos de arco, de acordo com a teoria corpuscular da luz de Newton; (iii) ou deflexão com um ângulo maior, pelo menos o dobro, cerca de 1,6 segundos de arco, de acordo com a nova teoria de distorção do espaço-tempo pela presença de um corpo muito massivo. Essas propostas foram divulgadas entre os astrônomos da época, e se organizaram expedições para a observação de eclipses em diversos locais, mas que invariavelmente foram frustradas devido a dificuldades como o mau tempo ou o estado de guerra na Europa. Os detalhes dessa história são narrados em alguns artigos dessa edição. Chamamos a atenção em particular ao relato do astrofísico português José Lemos, que se refere principalmente às expedições europeias, e ao artigo do astrofísico argentino Santiago Paolantonio, que resgata um episódio pouco conhecido, 
uma expedição à cidade de Cristina, em Minas Gerais, em 1912, comandada pelo diretor do Observatório Nacional de Córdoba, o americano Charles Perrine, que infelizmente esbarrou nas dificuldades do mau tempo. O papel de Henrique Morize, diretor do nosso Observatório Nacional, que também participou da expedição a Cristina, e que mais tarde escreveu sobre as excelentes condições observacionais em Sobral e participou do apoio à expedição inglesa, é descrito pelo físico e historiador da ciência Antonio Augusto Videira. Uma descrição mais detalhada dos trabalhos e equipamentos da expedição inglesa, com base em pesquisas nos arquivos britânicos, foi escrita pelo nosso colega Luis Carlos Bassalo Crispino, que tem se dedicado ao resgate de episódios da física no país.

Certos aspectos históricos das observações concomitantes em Sobral e na Ilha de Príncipe, na costa ocidental da África, são abordados na tradução de dois textos muito bem escolhidos pelos nossos colegas Marcel Novaes e Nelson Studart. Um desses textos, sobre o "encurvamento da luz", é capítulo de livro clássico, publicado por Arthur Eddington em 1922. Outro texto, em tradução de Marcel Novaes, refere-se a pesquisas históricas bem mais recentes, do astrofísico e historiador da ciência americano Daniel Kennefick, que nos aponta o rigor da análise de Eddington e colaboradores sobre os dados das placas fotográficas de Sobral. Kennefick é autor de um livro recente sobre o centenário do eclipse, cujo título, "No shadow of a doubt: The 1919 eclipse that confirmed Einstein's theory of relativity", não deixa margem a dúvidas. De qualquer forma, praticamente os mesmos valores angulares obtidos nos "céus do Brasil" foram também obtidos em observações subsequentes, e são atualmente confirmados pelos dados mais acessíveis da moderna radioastronomia.

A "vida secreta" dos eclipses, que fascinaram a humanidade desde os primeiros tempos, a contemporaneidade de descobertas como os exoplanetas, constituem o tema do nosso colega astrofísico Daniel Brito, que também traz reflexões sobre as diversas formas de obscurantismo que continuam perseguindo o nosso relacionamento com os astros. O artigo dos nossos colegas Cesar Lenzi, Pedro Pompeia e Nelson Studart, "A deflexão da luz pelo Sol: de Newton a Einstein", é leitura mandatória para os nossos alunos. Os autores analisam, de forma pedagógica, os cálculos realizados pelos predecessores de Einstein, incluindo os ingleses Michell e Cavendish, além dos cálculos do próprio Einstein. Também analisam a solução exata de Schwarzschild da equação de Einstein, que se tornou muito conhecida devido à previsão dos "buracos negros", referindo-se à influência desses cálculos sobre a formulação da moderna teoria da relatividade. Os desenvolvimentos posteriores às observações de Sobral deram origem à nova técnica de "lentes gravitacionais", com repercussões na cosmologia e na astrofísica modernas. Esse é o tema da exposição pedagógica dos nossos colegas astrofísicos José Ademir Lima e Rose Santos, que nos levam às fronteiras da pesquisa na área. Esses autores referem-se à descoberta de um quasar duplo, à formação de anéis relacionados a estrelas duplas, e às possibilidades de determinação da constante de Hubble e da quantidade de matéria escura no Universo, que são temas de enorme atualidade. 